\title{
Entire Course and Distinct Phases of Day-Lasting Depression of Miniature EPSC Amplitudes in Cultured Purkinje Neurons
}

\author{
Miho Murashima ${ }^{1}$ and Tomoo Hirano ${ }^{1,2}$ \\ ${ }^{1}$ Department of Biophysics, Graduate School of Science, Kyoto University, Sakyo-ku, Kyoto 606-8502, Japan, and \\ ${ }^{2}$ Core Research for Evolutional Science and Technology, Japan Science and Technology Corporation, Kawaguchi, \\ Saitama 332-0012, Japan
}

The cerebellar long-term depression (LTD) is the long-lasting reduction of transmission efficacy at the granule neuronPurkinje neuron (G-P) synapses and is a candidate mechanism for the motor learning. Despite extensive studies on its induction and expression mechanisms, it has not been known how long the LTD lasts. The LTD is accompanied by the decrease in the postsynaptic responsiveness to glutamate, the transmitter at G-P synapses. Therefore, during the LTD, the amplitude of miniature EPSCs (mEPSCs) at G-P synapses should decrease. We studied the depression of mEPSC amplitudes (DME) as a possible contributing factor for the LTD and found that the conditioning treatment of cultured cerebellar neurons with 50 $\mathrm{mm} \mathrm{K}^{+}$and $100 \mu \mathrm{M}$ glutamate, an analogous condition used to induce the LTD, induced the long-lasting DME. The mEPSC amplitudes recovered to the original level $48 \mathrm{hr}$ after the $5 \mathrm{~min}$

The cerebellar long-term depression (LTD) is the long-lasting reduction of transmission efficacy at the granule neuron-Purkinje neuron (G-P) synapses induced by repeated conjunctive activation of an inferior olivary neuron and granule neurons (Ito et al., 1982; Sakurai, 1987; Hirano, 1990a) and has been implicated as a cellular mechanism for the motor learning (see Ito, 1989; du Lac et al., 1995; Lisberger, 1998; Mauk et al., 1998). The mechanisms of the LTD induction have been studied extensively (for review, see Linden, 1994; Linden and Connor, 1995). It has been considered that the LTD is mainly expressed as the reduced sensitivity of postsynaptic AMPA subtype of ionotropic glutamate receptors (Ito et al., 1982; Hirano, 1991; Linden et al., 1991). For the induction, the LTD requires $\mathrm{Ca}^{2+}$ influx through voltagegated calcium channels (Sakurai, 1990; Linden et al., 1991; Konnerth et al., 1992; Kasono and Hirano, 1994) and simultaneous activation of AMPA subtype of ionotropic glutamate receptors and metabotropic glutamate receptors, specifically mGluR1 (Linden et al., 1991; Aiba et al., 1994; Conquet et al., 1994; Shigemoto et al., 1994).

Despite extensive studies on the induction and expression mechanisms of the LTD, there has been no report on its maintenance mechanisms. Without concrete experimental evidence, it

Received Dec. 10, 1998; revised May 24, 1999; accepted June 17, 1999.

This work was supported by grants from the Ministry of Education, Science, and Culture of Japan. We thank Drs. S. Nakanishi, R. Shigemoto, Y. Kubo, H. Okado, and M. Kengaku for discussion and advice.

Correspondence should be addressed to Tomoo Hirano, Department of Biophysics, Graduate School of Science, Kyoto University, Sakyo-ku, Kyoto 606-8502, Japan.

Copyright (C) 1999 Society for Neuroscience $\quad 0270-6474 / 99 / 197326-08 \$ 05.00 / 0$ conditioning treatment. Changing the duration of the conditioning revealed that the DME consisted of two distinct phases: the early phase lasting for a few hours and the late phase for $>1 \mathrm{~d}$. The latter was distinguished from the former by its requirement of prolonged conditioning treatment and syntheses of mRNA and protein for the induction. There were critical periods for mRNA and protein syntheses. The critical period for protein synthesis was much longer than that for mRNA synthesis. These results demonstrate that the DME lasts for 1-2 $d$ and that it consists of two phases, whose induction and maintenance mechanisms are distinct.

Key words: synaptic plasticity; miniature EPSCs; culture; cerebellum; Purkinje neuron; long-term depression; late phase; critical period; mRNA synthesis; protein synthesis has been claimed that there should be recovery of synaptic efficacy from the LTD, otherwise the synaptic transmission would be terminally depressed and further learning would be prevented (du Lac et al., 1995). Previous studies have shown that the transmission at G-P synapses potentiates after repetitive stimulation of granule neurons (Sakurai, 1987; Hirano, 1991; Salin et al., 1996). However, the potentiation has been ascribed to the enhanced transmitter release (Hirano, 1991; Salin et al., 1996; Linden, 1998), and thus it is not considered as the reversal process of the LTD. Without the recovery of postsynaptic responsiveness, the potentiation of the transmission efficacy by enhanced transmitter release is inefficient. Therefore, the recovery of postsynaptic responsiveness seems to be required. However, we have known neither how long the LTD lasts nor whether the postsynaptic responsiveness recovers from the LTD. Technical difficulties have prevented us from long-term measurement of the LTD. So far, the LTD has been monitored only for a few hours at most (Linden, 1996).

Here, we show that the conditioning treatment of the cerebellar culture with the solution containing high concentration of $\mathrm{K}^{+}$and glutamate, which mimics the condition for the LTD induction, induced the long-lasting depression of miniature EPSC (mEPSC) amplitudes (DME) in Purkinje neurons. Because the reduced postsynaptic sensitivity that should be reflected in the DME has been considered as a main cause of the LTD and the efficacy of synaptic transmission is determined by the amplitude of postsynaptic response to a single synaptic vesicle (mEPSC amplitude), the presynaptic release probability, and the number of release site, the DME can be an important factor for the LTD expression. We clarify the whole time course of DME and demonstrate that 
the DME consists of distinct early and late phases, whose induction conditions and maintenance mechanisms are different.

\section{MATERIALS AND METHODS}

Preparation of cultures. Primary cultures of cerebellar neurons were prepared from fetuses of a Wistar rat as described previously(Hirano, 1990a,b; Hirano and Kasono, 1993). Briefly, cerebella were dissected out from $\sim 18$-d-old fetuses, and meninges were removed. Then, cerebella were incubated for $7 \mathrm{~min}$ at room temperature $\left(20-25^{\circ} \mathrm{C}\right)$ in $\mathrm{Ca}^{2+}$ - and $\mathrm{Mg}^{2+}$-free HBSS (Life Technologies, Rockville, MD) containing 1\% trypsin (Life Technologies) and 0.05\% DNase (Sigma, St. Louis, MO). The tissue was washed three times with $\mathrm{Ca}^{2+}$-free HBSS containing 12 $\mathrm{mM} \mathrm{MgSO}_{4}$ and then dissociated by trituration with a fire-polished Pasteur pipette in $\mathrm{Ca}^{2+}$-free HBSS containing 0.05\% DNase. Cells were centrifuged at $1000 \times g$, and pelleted cells were resuspended in the serum-free defined medium. Three milliliters of the cell suspension obtained from 3-5 fetuses were plated in a plastic dish (diameter of 35 $\mathrm{mm}$ ) containing several pieces of heat-sterilized glass coverslips coated with $0.01 \%$ poly-D-lysine (Sigma). One-half of the culture medium was exchanged with fresh medium once every week.

Electrophysiology. Patch-clamp recordings from Purkinje neurons grown in culture for 4-5 weeks were performed at room temperature $\left(20-24^{\circ} \mathrm{C}\right)$ as described previously (Hirano and Hagiwara, 1988; Hirano and Kasono, 1993). A coverslip with cultured neurons grown on it was put in the recording chamber on the stage of a microscope (Diaphot TMD-300; Nikon, Tokyo, Japan). Whole-cell recordings were made with a CEZ-2300 amplifier (Nihon Kohden, Tokyo, Japan). Neurons with round somata of $20 \mu \mathrm{m}$ or larger diameter with wide dendrites were used for recording. They were identified as Purkinje neurons (Hirano and Ohmori, 1986). The composition of the external saline was (in mM): 145 $\mathrm{NaCl}, 5 \mathrm{KOH}, 2 \mathrm{CaCl}_{2}, 1 \mathrm{MgCl}_{2}, 10$ glucose, and $10 \mathrm{HEPES}, \mathrm{pH}$ 7.4. One micromolar tetrodotoxin (TTX) and $20 \mu \mathrm{M}$ bicuculline were added for recording mEPSCs to suppress action potentials and GABAergic inhibitory postsynaptic currents, respectively. The composition of internal solution was (in $\mathrm{mm}$ ): $140 \mathrm{D}$-glucuronate, $7 \mathrm{CsCl}, 155 \mathrm{CsOH}, 5$ EGTA, and 10 HEPES, pH 7.2. The electrode resistance was 4-6 M $\Omega$. Only the recordings with input resistance $>100 \mathrm{M} \Omega$ and series resistance $<25 \mathrm{M} \Omega$ were accepted. In the double recording experiments, the $\mathrm{K}$ glucuronate internal solution was used (in mM): 140 D-glucuronate, 151 $\mathrm{KOH}, 7 \mathrm{KCl}, 0.5 \mathrm{EGTA}$, and $10 \mathrm{HEPES}, \mathrm{pH}$ 7.2. Slightly smaller patch pipettes with the electrode resistance of $5-10 \mathrm{M} \Omega$ were used. The duration of the whole-cell recording was minimized $(<2 \mathrm{~min})$ to prevent wash out of the cytosol. Only the recordings with the input resistance $>100 \mathrm{M} \Omega$ and the series resistance $<30 \mathrm{M} \Omega$ were accepted. The second recording was accepted only when there was neither visible damage to the previously patched neuron nor significant change in the input resistance and the series resistance. The success rate of the double recording experiment was $<10 \%$. The mEPSCs were recorded at $-80 \mathrm{mV}$. All the junction potentials were corrected.

In one set of experiments, mEPSCs were recorded from 8 to 17 Purkinje neurons grown on a few coverslips in a single culture dish. After recording, the coverslips were discarded. Then, the conditioning treatment (see below) was applied, and mEPSCs were recorded from Purkinje neurons grown on coverslips left in the same culture dish. When mEPSCs were recorded twice from a single Purkinje neuron, after recording mEPSCs, the coverslip was returned to the culture dish, and the conditioning treatment was applied in the same way.

The evoked EPSCs were induced by stimulating a granule neuron located close to the recorded Purkinje neuron. A granule neuron was stimulated with a negative voltage pulse $(1-10 \mathrm{~V}, 100 \mu \mathrm{sec})$ applied to a patch pipette placed adjacent to it and containing extracellular solution. The glutamate response in a Purkinje neuron was induced by applying a negative voltage pulse to a patch pipette located $\sim 20 \mu \mathrm{m}$ away from a primary dendrite and containing $10 \mathrm{~mm}$ glutamate and $10 \mathrm{~mm}$ HEPES, pH 7.3.

Conditioning treatment. For the conditioning treatment, the culture medium was replaced by the external saline containing $50 \mathrm{~mm} \mathrm{KCl} \mathrm{in}$ place of $50 \mathrm{~mm} \mathrm{NaCl}$ and containing agonists and/or antagonists for glutamate receptors. After this treatment, cultured neurons were bathed again in the same culture medium in which the neurons had been cultured. In the experiments using actinomycin D and anisomycin, neurons were treated with drug-containing medium in the same way. AMPA, 6-cyano-7-nitroquinoxaline-2,3-dione (CNQX), $(R, S)-\alpha$-methyl-4carboxyphenylglycine (MCPG), and (1S,3R)-1-aminocyclopentane-1,3dicarboxylic acid (tACPD) were obtained from Tocris (Bristol, UK), and
TTX, bicuculline, anisomycin, and actinomycin D were obtained from Sigma.

Analyses of mEPSCs. The mean amplitudes of mEPSCs before and at various times after the conditioning treatment were obtained as follows. The mean amplitude of mEPSCs in each cell was calculated from 150 to 1000 mEPSCs recorded for $10-30 \mathrm{sec}$. The mean amplitudes of mEPSCs of Purkinje neurons recorded before the treatments were further averaged and defined as $100 \%$ for each set of experiments, and the mean amplitude of mEPSCs for each cell was compared with the average. The results presented (mean \pm SEM and the number of cells) are summary of data from three to five sets of recordings, unless otherwise stated. In each experiment, the mEPSCs recorded before and after the treatment were shuffled and analyzed blind at least in one set of recordings using neurons in a single culture dish. Results obtained blind were comparable with others. Student's $t$ test was used for the statistical analyses.

\section{RESULTS}

\section{Depression of mEPSC amplitudes}

We used the amplitudes of mEPSCs as a measure of the postsynaptic sensitivity. The mEPSC is the response to a single synaptic vesicle, and its amplitude should decrease if the postsynaptic sensitivity is reduced. Because the LTD is expressed as the reduced postsynaptic sensitivity to glutamate at least partly, we studied the time course of the mEPSC amplitudes after the conditioning treatments. We recorded mEPSCs from cultured Purkinje neurons. Figure $1 A$ (Before) shows the sample traces of mEPSCs and their amplitude histogram. Considerable variation in mEPSC amplitudes was observed in a single Purkinje neuron. The mean amplitude of mEPSCs was $9.5 \pm 0.2 \mathrm{pA}$ (mean $\pm \mathrm{SEM}$; 334 cells). The rise time and half-decay time of the mEPSCs were $2.9 \pm 0.2$ and $5.2 \pm 0.4 \mathrm{msec}(22$ cells), respectively. The mean frequency of mEPSCs was $13.5 \pm 1.1 \mathrm{~Hz}$. In the culture, only excitatory neurons innervating Purkinje neurons are granule neurons, and AMPA receptors, but not NMDA receptors, contribute to the transmission at the synapses (Hirano and Hagiwara, 1988; Hirano and Kasono, 1993). Therefore, the recorded mEPSCs were considered to be mediated by postsynaptic AMPA receptors at the G-P synapses.

In situ, the LTD is induced by the repeated conjunctive activation of an inferior olivary neuron and granule neurons. In vitro, the former can be replaced by direct depolarization of a postsynaptic Purkinje neuron (Hirano, 1990b; Crepel and Jaillard, 1991) and the latter by direct glutamate application (Linden et al., 1991). In the present study, to induce the DME, we treated the cultured neurons for 5 min with the solution containing $50 \mathrm{~mm}$ $\mathrm{K}^{+}$, which induces depolarization, and $100 \mu \mathrm{M}$ glutamate. The mEPSC amplitudes recorded from numbers of Purkinje neurons before and at various times after the conditioning treatment were measured (Fig. 1). We monitored the mEPSC amplitudes for 1 week. In four of five sets of experiments, the conditioning treatments with $50 \mathrm{~mm} \mathrm{~K}^{+}$and $100 \mu \mathrm{M}$ glutamate for 5 min reduced the mEPSC amplitudes, and the DME lasted for $>36 \mathrm{hr}$. The mEPSC amplitudes recovered by $48 \mathrm{hr}$ and stayed at the original level thereafter (Fig. $1 B$ ). The mEPSC amplitudes were $71 \pm 2 \%$ of those before the conditioning between 1 and $3 \mathrm{hr}$ after the conditioning (at $t=1-3 \mathrm{hr} ; 87$ cells), $77 \pm 8 \%$ at $t=23-25 \mathrm{hr}(30$ cells), and $107 \pm 8 \%$ at $t=47-49 \mathrm{hr}$ (20 cells). The time course of mEPSCs was unchanged by the conditioning (Fig. $1 C, D$ ). The rise time and half-decay time of the mEPSCs after the conditioning were $2.5 \pm 0.2$ and $5.1 \pm 0.4 \mathrm{msec}$ at $t=1-3 \mathrm{hr}(20$ cells $)$ and $2.9 \pm 0.2$ and $5.6 \pm 0.3 \mathrm{msec}$ at $t=23-25 \mathrm{hr}$ (14 cells), respectively. None of holding current, input resistance, and series resistance were changed by the conditioning. The holding current was $71.9 \pm 7.1 \mathrm{pA}$ before the conditioning, $76.8 \pm 8.5 \mathrm{pA}$ at $t=$ 
A

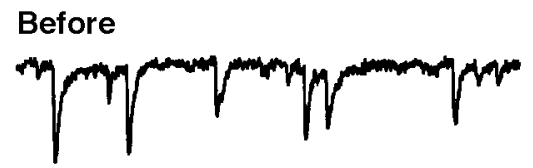
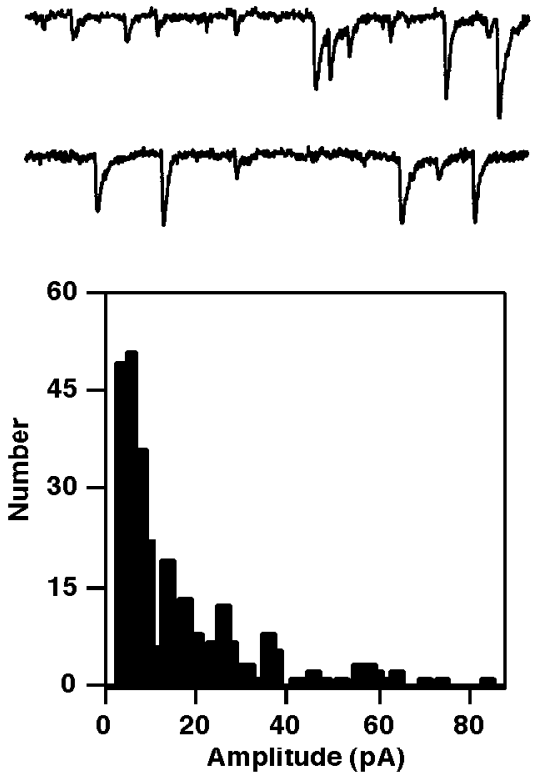

$2 \mathrm{hr}$
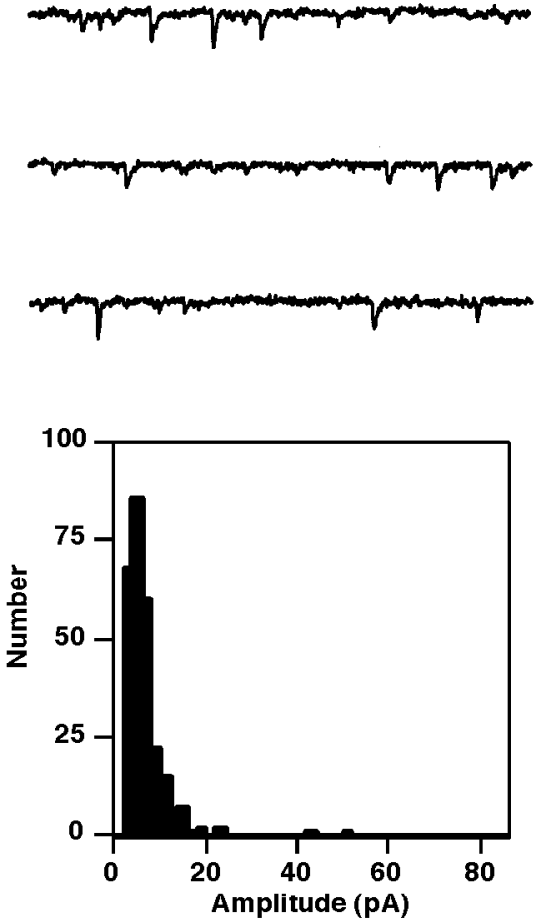

$168 \mathrm{hr}$

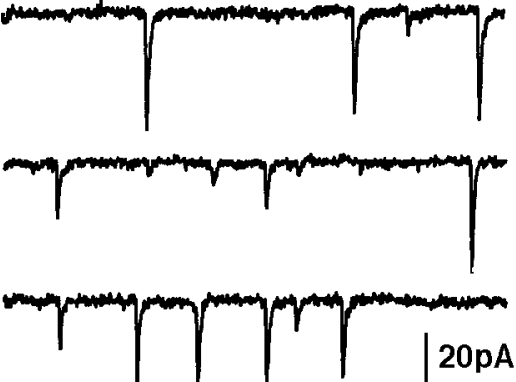

$100 \mathrm{msec}$

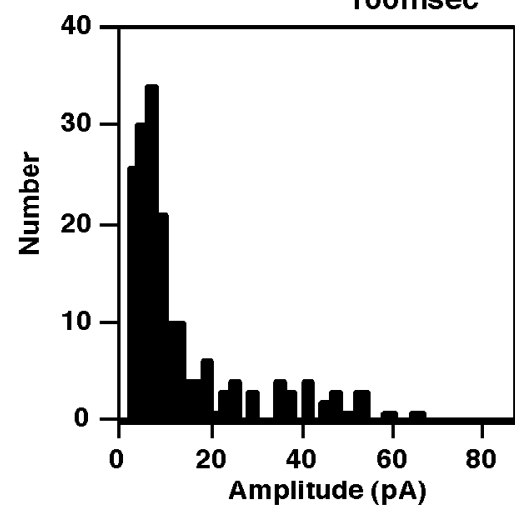

B

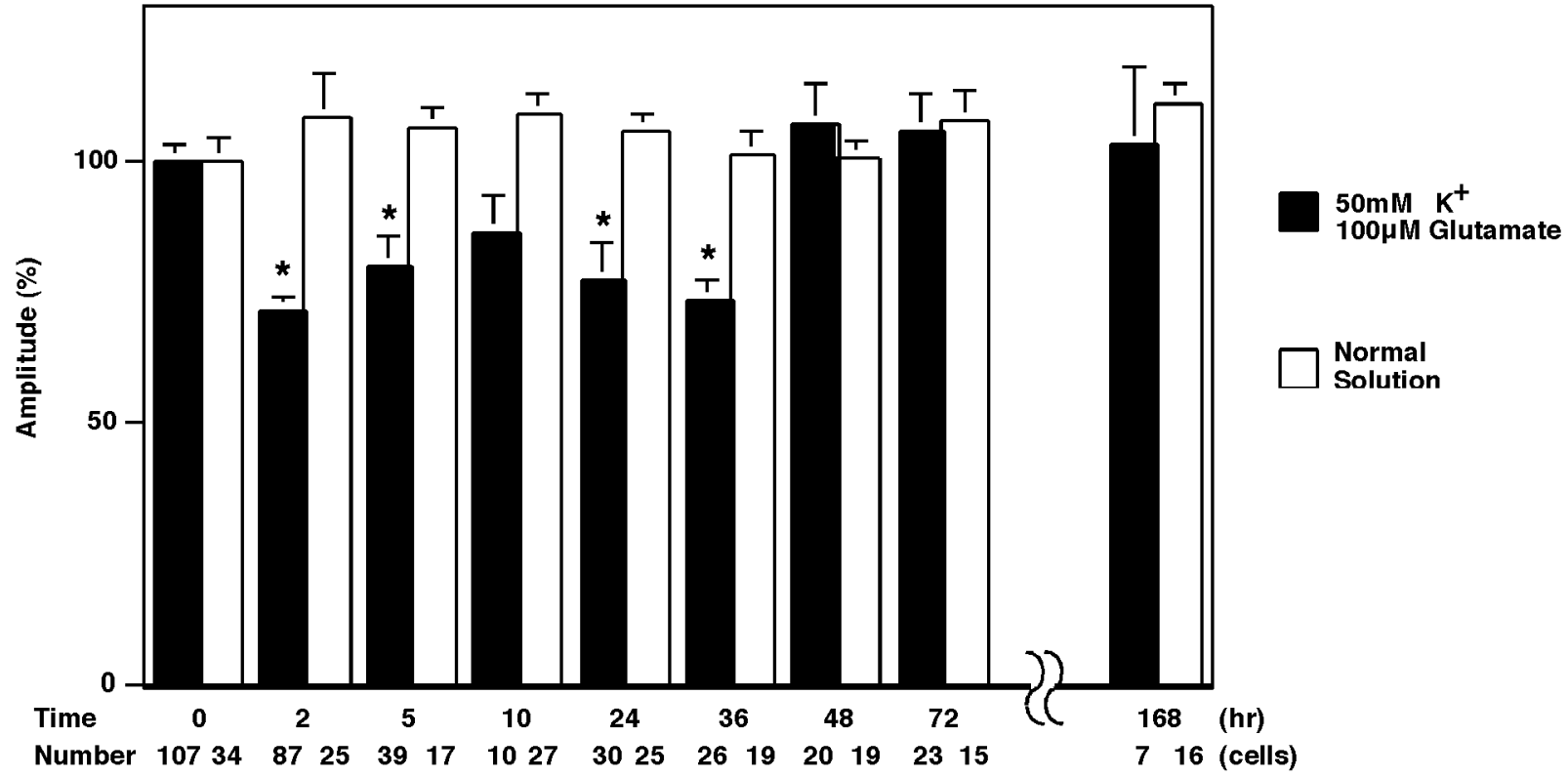

C
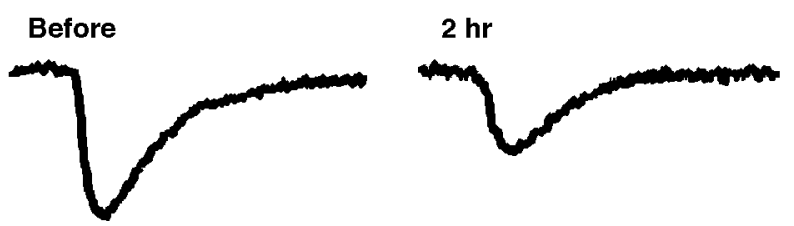

$24 \mathrm{hr}$

D
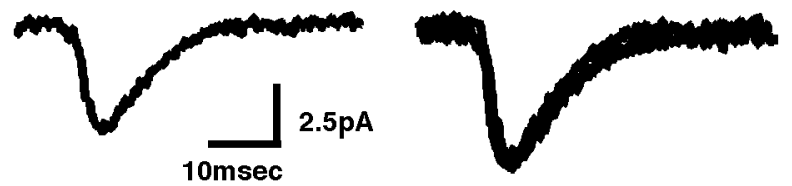

Figure 1. The mEPSCs in cultured Purkinje neurons and the DME. $A$, Representative traces and amplitude histograms of mEPSCs before and 2 and $168 \mathrm{hr}$ after the conditioning treatment. $B$, Changes of mEPSC amplitudes by the 5 min conditioning treatment with $50 \mathrm{~mm} \mathrm{~K}^{+}$and $100 \mu \mathrm{M}$ glutamate. Mean amplitudes of mEPSCs after the conditioning treatment were compared with those before the conditioning (shown as $0 \mathrm{hr}$ ). The data presented were obtained between $1 \mathrm{hr}$ before and $1 \mathrm{hr}$ after the indicated time. ${ }^{*} p<0.01$ indicates the data showing significant differences against the value before the conditioning. Results of the control treatment with the normal external saline are also presented. The number of recorded cells is shown at the bottom. $C$, Averaged traces of $20 \mathrm{mEPSCs}$ before and 2 and $24 \mathrm{hr}$ after the conditioning treatment. $D$, Three traces in $\mathrm{C}$ are scaled and superimposed. 
A

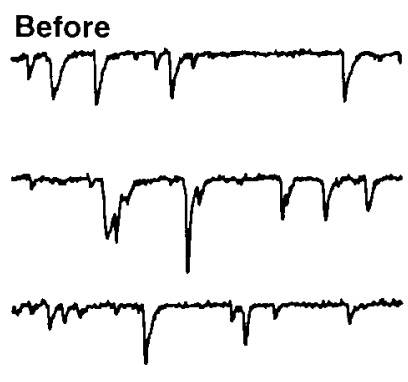

C

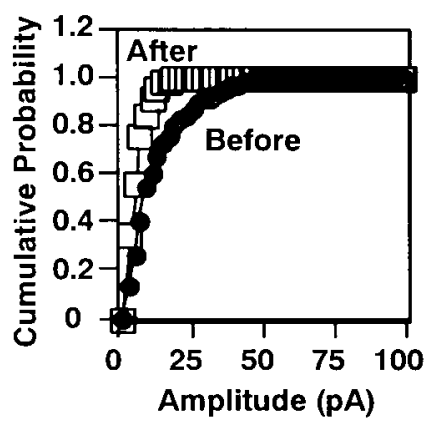

B
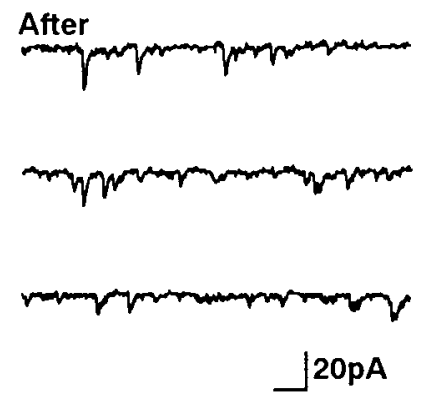

$100 \mathrm{msec}$

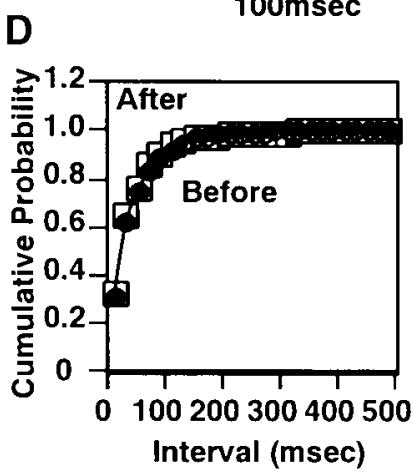

Figure 2. The mEPSCs from a single Purkinje neuron before and after the conditioning treatment. $A, B$, Representative traces before and $6 \mathrm{hr}$ after the conditioning treatment, respectively. $C$, Cumulative probability of amplitudes before (filled circles) and after (open squares) the conditioning treatment. $D$, Cumulative probability of intervals before and after the conditioning.

$1-3 \mathrm{hr}$, and $74.2 \pm 7.1 \mathrm{pA}$ at $t=23-25 \mathrm{hr}$. The input resistance was $467 \pm 27 \mathrm{M} \Omega$ before the conditioning, $457 \pm 35 \mathrm{M} \Omega$ at $t=$ 1-3 hr, and $463 \pm 47 \mathrm{M} \Omega$ at $t=23-25 \mathrm{hr}$. The series resistance was $16.3 \pm 0.6 \mathrm{M} \Omega$ before the conditioning, $18.8 \pm 0.6 \mathrm{M} \Omega$ at $t=$ $1-3 \mathrm{hr}$, and $16.9 \pm 1.0 \mathrm{M} \Omega$ at $t=23-25 \mathrm{hr}$. The mEPSC frequency was much more variable than the mEPSC amplitudes (ranging from 1.7 to $61.1 \mathrm{~Hz}$ ). We did not find consistent tendency to increase or decrease in the frequency of mEPSCs after the conditioning treatment. Control treatment of cultured neurons with the normal external saline did not affect the mEPSC amplitudes (Fig. 1B). Thus, the recovery at $t=47-49 \mathrm{hr}$ is considered as neither the developmental change nor recovery from the damage by the solution exchange. These results demonstrated that the conditioning treatment induced the DME without affecting its time course and that the DME lasted at least $1.5 \mathrm{~d}$ and ended by $2 \mathrm{~d}$.

Because the distribution of mEPSC amplitudes varied among Purkinje neurons, we examined whether the mEPSC amplitudes in a single Purkinje neuron were reduced by the conditioning treatment. After recording the mEPSCs, the position and morphology of each Purkinje neuron were noted. Then, it was returned to the culture medium, and the conditioning treatment was applied. We recorded the mEPSCs again from the same Purkinje neuron between 2 and $24 \mathrm{hr}$ after the conditioning. The mEPSC amplitudes were reduced by the conditioning treatment $(72 \pm$ $5 \%$; 9 cells), whereas the intervals of mEPSCs were unchanged (Fig. 2). When mEPSCs were recorded twice from a single Purkinje neuron without the conditioning, the mean amplitude of mEPSCs was unchanged ( $97 \pm 5 \% ; 8$ cells). These results suggest that the DME observed in the population of Purkinje neurons

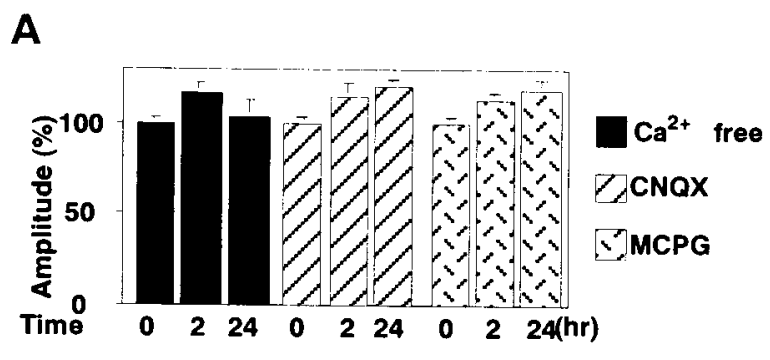

Number $21 \quad 2517 \quad 312021 \quad 35 \quad 20 \quad 24$ (cells)
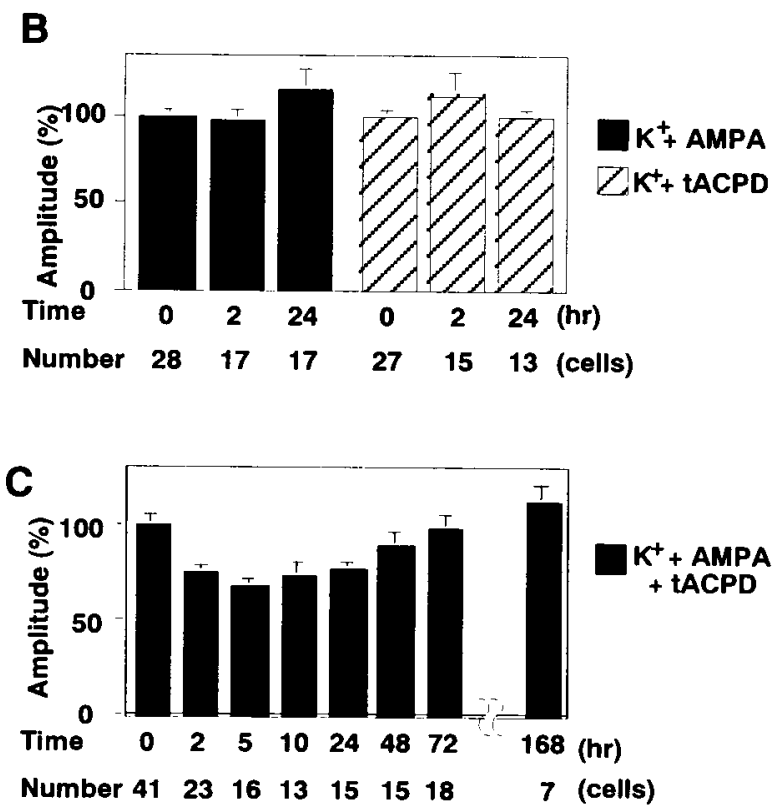

Figure 3. Conditions to induce the DME. $A$, Mean amplitudes of mEPSCs before and after the conditioning treatment with the solution lacking $\mathrm{Ca}^{2+}$ or containing either $10 \mu \mathrm{M}$ CNQX or $1 \mathrm{mM}$ MCPG. $B$, Mean amplitudes of mEPSCs before and after the conditioning treatment with $50 \mathrm{mM} \mathrm{K}^{+}$and either $10 \mu \mathrm{M}$ AMPA or $100 \mu \mathrm{M}$ tACPD. $C$, The change of mEPSC amplitudes induced by the conditioning treatment with $50 \mathrm{mM} \mathrm{K}^{+}, 10 \mu \mathrm{M}$ AMPA, and $100 \mu \mathrm{M} \mathrm{tACPD}$.

parallels that of a single Purkinje neuron. Therefore, we monitored mEPSC amplitudes in the population of Purkinje neurons in the following experiments.

\section{Conditions to induce the DME}

We next examined whether the $\mathrm{Ca}^{2+}$ influx induced by depolarization and simultaneous activation of AMPA receptors and mGluRs are required to induce the day-lasting DME. They were shown to be necessary for the LTD induction in previous studies (Sakurai, 1990; Linden et al., 1991; Konnerth et al., 1992; Aiba et al., 1994; Conquet et al., 1994; Kasono and Hirano, 1994; Shigemoto et al., 1994), although the LTD was monitored only for a few hours. The DME was absent at both $t=1-3$ and 23-25 hr when the conditioning solution lacked $\mathrm{Ca}^{2+}$ or contained either CNQX, an antagonist for AMPA receptors, or MCPG, an antagonist for mGluRs (Fig. 3A). Application of $50 \mathrm{mM} \mathrm{K}^{+}$with either AMPA, an agonist for AMPA receptors, or tACPD, an agonist for mGluRs, did not induce the DME (Fig. 3B). On the other hand, combined application of $50 \mathrm{mM} \mathrm{K}^{+}$, AMPA, and tACPD induced the DME, whose time course was similar to that induced by the application of $50 \mathrm{~mm} \mathrm{~K}^{+}$and glutamate (Fig. 3C). These results confirmed that the effect of glutamate was mediated 

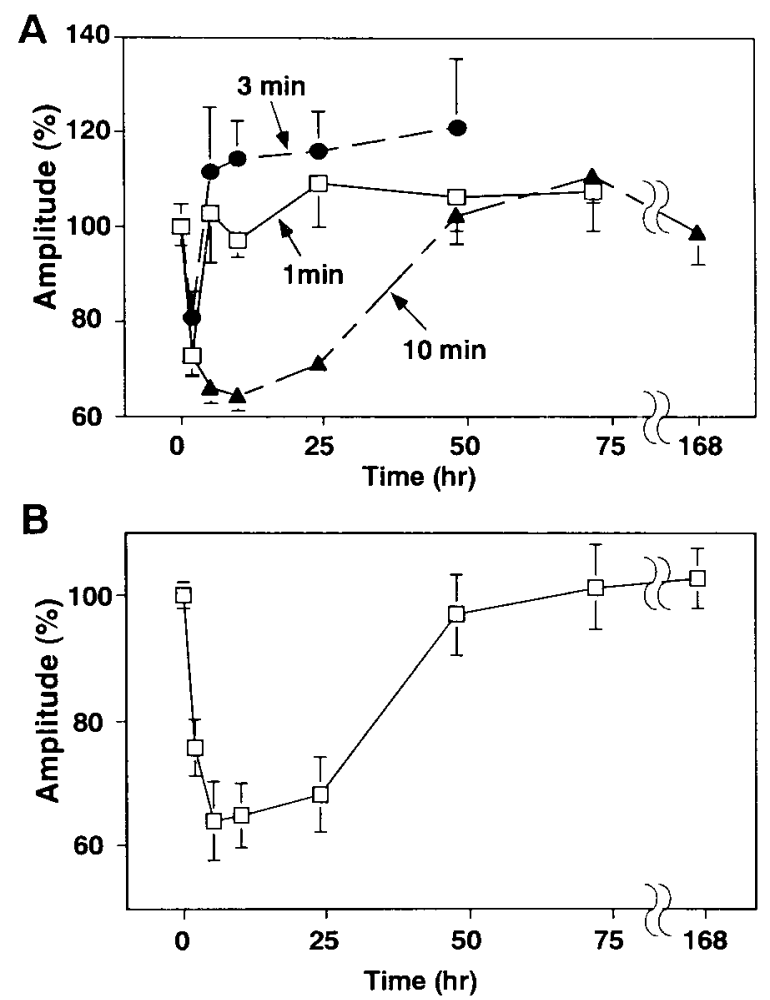

Figure 4. Duration of the DME. A, The change of mEPSC amplitudes induced by the conditioning treatment with $50 \mathrm{mM} \mathrm{K}^{+}$and $100 \mu \mathrm{M}$ glutamate for 1,3 , and $10 \mathrm{~min}$. $B$, The change of mEPSC amplitudes induced by 5 min treatments twice with a 30 min interval. Each point represents data from 9 to 35 cells.

through AMPA receptors and mGluRs and through neither NMDA receptors nor nonspecific action. Together, $\mathrm{Ca}^{2+}$ influx, simultaneous activation of AMPA receptors and mGluRs are required for the induction of day-lasting DME, as well as for that of the LTD previously observed in shorter time scale.

\section{Duration of the DME}

So far, the conditioning treatment was for $5 \mathrm{~min}$. To inquire into whether there is a shorter form of the DME or the further long-lasting DME, we varied the duration of conditioning treatment. The duration of the DME differed depending on the duration of conditioning treatment. When the conditioning treatment was shortened to $1 \mathrm{~min}$, the DME lasted for only 2-3 hr (Fig. 4A). The mean amplitudes of mEPSCs decreased to $73 \pm$ $4 \%$ at $t=1-3 \mathrm{hr}$ ( 23 cells) of those before the conditioning, a comparable level with that induced by the $5 \mathrm{~min}$ conditioning. However, the mEPSC amplitudes recovered to $103 \pm 10 \%$ at $t=$ 4-6 hr (22 cells). The DME was not observed later than $5 \mathrm{hr}$. Three minutes of conditioning also did not induce the late phase of the DME (Fig. 4A). We also prolonged the conditioning treatment and examined its effect. The duration of the DME induced by $10 \mathrm{~min}$ conditioning was similar to that induced by 5 min conditioning (Fig. 4A). The mean amplitude of mEPSCs recovered to the level before the conditioning in $2 \mathrm{~d}$. Prolongation of the conditioning duration did not prolong the duration of the DME. In the long-term potentiation (LTP) in the hippocampal CA1 region and heterosynaptic facilitation in Aplysia, repetitive stimulation is used to induce the late phase (Montarolo et al., 1986; Frey et al., 1988; Nguyen et al., 1994; Abel et al., 1997; Frey and Morris, 1997; Martin et al., 1997). Assuming that repetitive

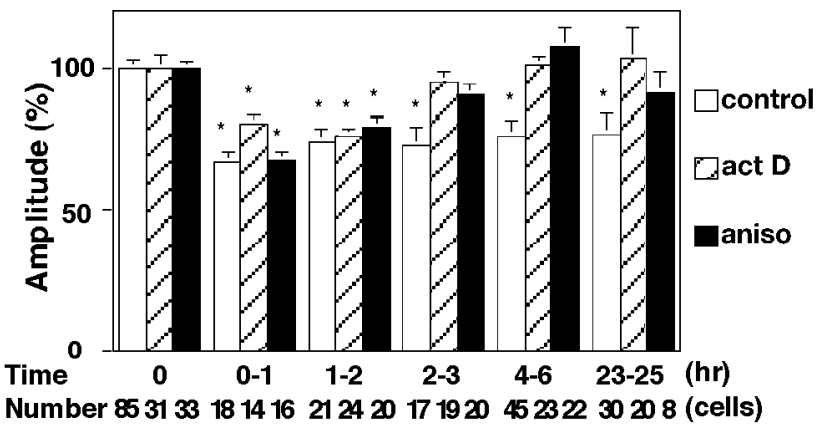

Figure 5. Dependency of the late phase of the DME on mRNA and protein syntheses. The change of mEPSC amplitudes when cultured neurons were treated for $5 \mathrm{~min}$ with either $20 \mu \mathrm{M}$ actinomycin D (act D) or $10 \mu \mathrm{M}$ anisomycin (aniso) immediately after the conditioning. The result with neither actinomycin D nor anisomycin treatment is shown for comparison (control).

conditioning might prolong the duration of DME to $>2 \mathrm{~d}$, we performed $5 \mathrm{~min}$ treatments twice with a $30 \mathrm{~min}$ interval. However, the duration of DME was not prolonged further (Fig. 4B). These results suggest that the late phase of DME is distinct from the early phase and is induced only by the prolonged conditioning treatment.

\section{Dependency of the late phase on mRNA and protein syntheses}

The next question to come is what mechanisms differentiate the late phase induced only by the conditioning treatment for $>5 \mathrm{~min}$ from the early phase inducible by the shorter conditioning. In the LTP in the hippocampal CA1 region, the late phase $(>3 \mathrm{hr}$ after the conditioning stimulus) is reported to depend on mRNA and protein syntheses (Frey et al., 1988; Nguyen et al., 1994; Frey and Morris, 1997). The LTD of glutamate responsiveness in a Purkinje neuron is suppressed at 1-2 $\mathrm{hr}$ after the induction by inhibitors of mRNA or protein synthesis (Linden, 1996). We therefore examined the effect of actinomycin D and anisomycin, respective inhibitors of mRNA and protein syntheses, on the day-lasting late phase of DME, as well as on the early phase. Five minutes of treatment with either actinomycin D or anisomycin immediately after the 5 min conditioning treatment with $50 \mathrm{~mm}$ $\mathrm{K}^{+}$and $100 \mu \mathrm{M}$ glutamate suppressed the late phase, but not the early phase, of DME (Fig. 5). These results indicate that the induction of the late phase of DME is dependent on mRNA and protein syntheses but that of the early phase is not.

\section{Critical periods for mRNA and protein syntheses}

We next examined whether there are critical periods for mRNA and protein syntheses necessary for the induction and possibly for the maintenance of the late phase of DME. In the LTP in the hippocampal CA1 region and in the heterosynaptic facilitation of Aplysia, it is reported that there are critical periods for mRNA and protein syntheses (Montarolo et al., 1986; Nguyen et al., 1994; Frey and Morris, 1997). As for the cerebellar LTD, Linden (1996) showed that the application of anisomycin $30 \mathrm{~min}$ after the induction did not affect the LTD of glutamate responsiveness. We varied the timing of treatment with actinomycin D or anisomycin and examined their effects. Treatment with actinomycin D $30 \mathrm{~min}$ after the conditioning suppressed the late phase, whereas that at 50 min after the conditioning did not (Fig. 6A). These results show that mRNA synthesis necessary for the induction of the late phase of DME lasted $>30 \mathrm{~min}$ and finished by $50 \mathrm{~min}$. On the 

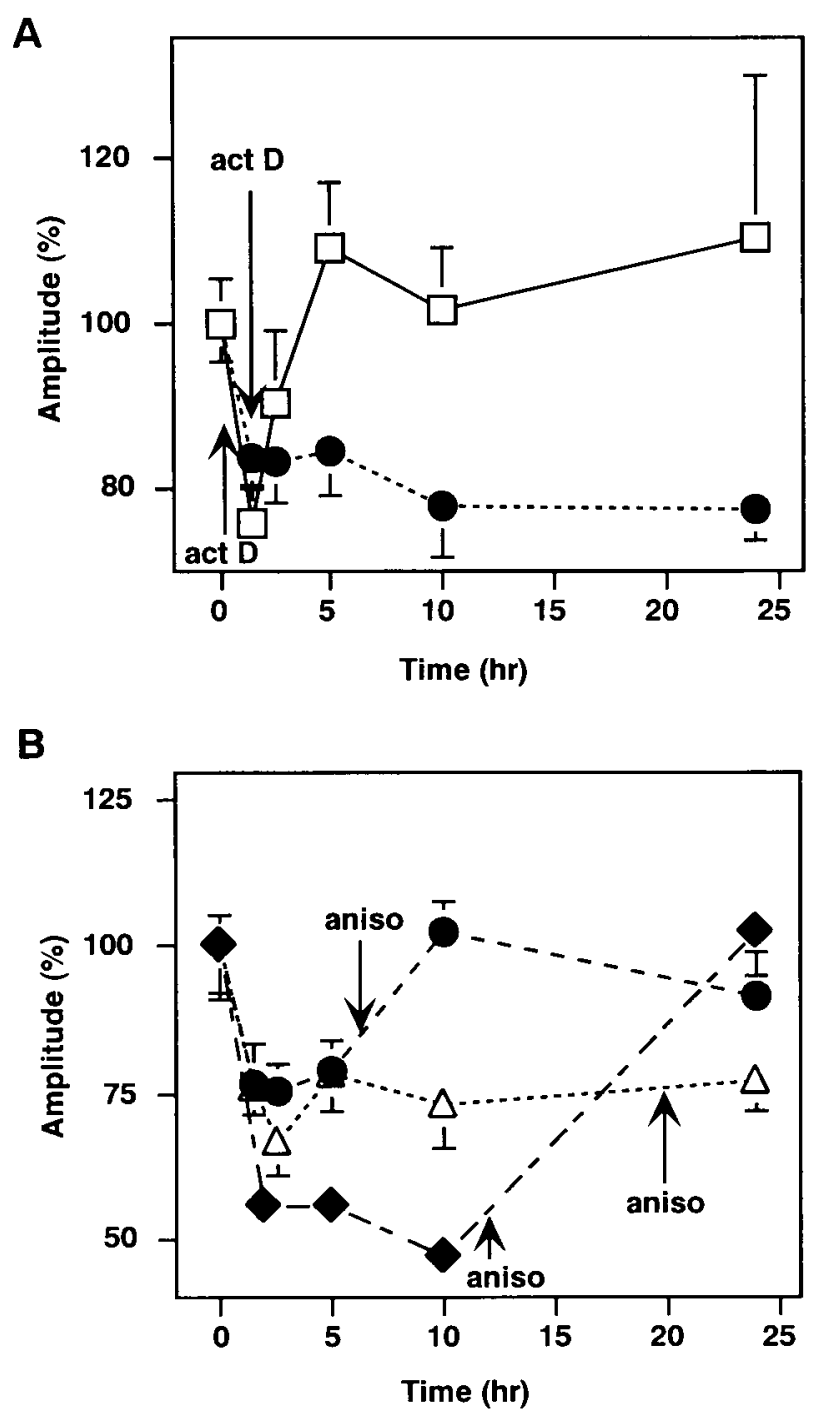

Figure 6. Critical periods for mRNA and protein syntheses. The changes of mEPSC amplitudes when cultured neurons were treated for 5 min with either $20 \mu \mathrm{M}$ actinomycin D 30 or $50 \mathrm{~min}$ after the conditioning $(A)$ or with $10 \mu \mathrm{M}$ anisomycin 6,12 , and $20 \mathrm{hr}$ after the conditioning $(B)$. The arrows indicate the timing of actinomycin $\mathrm{D}$ or anisomycin application. The data for anisomycin treatment at $12 \mathrm{hr}$ are summary of two sets of recordings. Each point represents data from 7 to 32 cells.

other hand, treatment with anisomycin 50 min or $3 \mathrm{hr}$ after the conditioning suppressed the late phase (data not shown). We further delayed the timing of anisomycin treatment to 6 or $12 \mathrm{hr}$ after the 5 min conditioning. The mEPSC amplitudes recovered to the original level at $t=10$ and $24 \mathrm{hr}$, respectively (Fig. 6B). However, when cultured neurons were treated with anisomycin at $20 \mathrm{hr}$ after the conditioning, the DME was seen at $24 \mathrm{hr}$ (Fig. 6B). The DME still persisted at $36 \mathrm{hr}$ after the conditioning (data not shown). These results suggest that the critical period for protein synthesis is longer than $12 \mathrm{hr}$ and shorter than $20 \mathrm{hr}$.

\section{DISCUSSION}

\section{Long-range monitoring of the DME}

In the present study, we monitored the DME induced by conditioning treatments in the population of Purkinje neurons for days. The mEPSC amplitudes should reflect the postsynaptic sensitiv- ity, which has been considered as an expression site of the cerebellar LTD (Linden and Connor, 1995). So far, the LTD has been monitored with the amplitudes of EPSPs or EPSCs (for examples: Sakurai, 1987; Hirano, 1990a,b; Crepel and Jaillard, 1991). Alternatively, the response to iontophoretically applied glutamate (the transmitter) has been used (Linden et al., 1991; Shigemoto et al., 1994; Linden, 1996). With these previous methods, the recording duration has been limited to a few hours because of the difficulty in maintaining a good intracellular recording condition for a long time. The hippocampal LTP has been monitored with field EPSPs for up to a few weeks in living animals (Abraham et al., 1993). In Aplysia neuronal culture, intracellular recordings from the same sensory neuron-motor neuron pair twice with an interval of $24 \mathrm{hr}$ have been performed (Montarolo et al., 1986; Martin et al., 1997). However, application of these methods to the cerebellar LTD is technically difficult.

The reason to use mEPSC amplitude as a measure of postsynaptic responsiveness is that the mean amplitude of mEPSCs is less variable than that of evoked EPSCs or responses to iontophoretically applied glutamate. The EPSC amplitudes in cultured Purkinje neurons evoked by the stimulation of a granule neuron vary considerably, ranging from 20 to $>800 \mathrm{pA}$ (Hirano and Hagiwara, 1988), probably depending on the number of synapses formed between each G-P pair. The response to iontophoretically applied glutamate is also variable and highly dependent on the position of the glass pipette containing glutamate. It is difficult to set the same condition for different Purkinje neurons. We recorded EPSCs and responses to iontophoretically applied glutamate on Purkinje neurons before and after the conditioning. However, we failed to detect significant changes in their amplitudes because of the large variation.

On the other hand, there is a problem in using mEPSCs as a measure of postsynaptic responsiveness. Not only the change in postsynaptic responsiveness but also that in the amount of transmitter per synaptic vesicle should affect the mEPSC amplitude. However, the latter has not been reported as a mechanism of synaptic plasticity so far as we know. Another limitation to use mEPSC amplitudes is that the evoked EPSC amplitudes and mEPSC amplitudes may not co-vary. Although the mEPSC amplitude is an important factor to determine the EPSC amplitude, the latter is also affected by the presynaptic release probability and the number of release sites. The present study is concerned about the postsynaptic responsiveness, and it does not provide information about the possible presynaptic change in the transmitter release process.

The conditioning treatment with $50 \mathrm{mM} \mathrm{K}^{+}$and $100 \mu \mathrm{M}$ glutamate reduced the mEPSC amplitudes for $>36 \mathrm{hr}$. The validity of using mEPSC amplitudes in population of Purkinje neurons was confirmed by recording mEPSCs twice from the same neurons. The DME was observed in a single Purkinje neuron. The mEPSC amplitude may be affected by the change in dendritic cable properties or excitability, although it was not noticed. The DME was not accompanied by the change in the time course of mEPSCs, the input resistance, and the holding current. The induction of DME required $\mathrm{Ca}^{2+}$ and simultaneous activation of AMPA subtype and metabotropic glutamate receptors. Previous studies showed that the LTD is not accompanied by the change in the time course of EPSPs (Sakurai, 1987) and that the induction of LTD requires $\mathrm{Ca}^{2+}$ and simultaneous activation of AMPA and metabotropic glutamate receptors (Sakurai, 1990; Linden et al., 1991; Konnerth et al., 1992; Aiba et al., 1994; Conquet et al., 1994; Kasono and Hirano, 1994; Shigemoto et al., 1994). Thus, 
properties of DME are similar to those of LTD monitored with different methods. Monitoring amplitudes of miniature postsynaptic currents will be promising in analyses of molecular mechanism of long-lasting synaptic plasticity accompanied by changes in postsynaptic responsiveness, because the method is simple and applicable to culture preparations in which pharmacological and molecular biological manipulations of cells are feasible.

\section{Recovery from the DME}

The DME lasted as long as $36 \mathrm{hr}$, and the mEPSC amplitudes returned to the original level by $48 \mathrm{hr}$ after the conditioning. Thus, the recovery of postsynaptic responsiveness from the depression was demonstrated. It should be important for the efficient regulation of transmission efficacy. The duration of the DME is relatively short compared with the week-lasting duration of LTP in dentate gyrus (Abraham et al., 1993). We tried 5 min treatments twice seeking for further long-lasting DME. However, the duration of the DME was not prolonged. Although other protocols of conditioning stimulation might induce the DME lasting longer than $2 \mathrm{~d}$, our attempt to induce the DME longer than $2 \mathrm{~d}$ has been unsuccessful so far. At this point, it is unclear whether the time course of DME exactly parallels that of the LTD. However, the former should at least be a contributing factor for the latter.

\section{Distinct two phases of the DME}

The DME consisted of distinct early and late phases, and the induction of the late phase was dependent on the prolonged conditioning. These results suggest that the coactivation of a climbing fiber and parallel fibers in limited time may induce the early phase only, whereas the repeated longer coactivation may induce the late phase. We also found that the late phase of DME was dependent on mRNA and protein syntheses. Linden (1996) has reported that mRNA and protein synthesis inhibitors suppress the depression of glutamate responsiveness 1-2 hr after the induction. The onset of protein synthesis-dependent late phase was shifted late slightly (2-3 hr after the induction) in our study. Differences in the way of induction and/or monitoring might have caused the difference.

As for the LTP in the hippocampal CA1 region, one or two 100 $\mathrm{Hz}$ train(s) of stimulation induce(s) only the early phase, although three or four $100 \mathrm{~Hz}$ trains induce the late phase, as well (Abel et al., 1997; Frey and Morris, 1997). The late phase is dependent on protein and mRNA syntheses (Frey et al., 1988; Nguyen et al., 1994; Frey and Morris, 1997). Overexpression of an inhibitory form of the regulatory subunit of protein kinase A (Abel et al., 1997) or targeted mutation of the cAMP-responsive element-binding protein (Bourtchuladze et al., 1994), which specifically impair the late, but not the early, phase of LTP, results in deficiency in the long-term, but not short-term, memory. As for the heterosynaptic facilitation in Aplysia, the short-term facilitation lasting for minutes was induced by a single application of serotonin (5-HT) and the long-term facilitation lasting $>24 \mathrm{hr}$ by five applications of 5-HT. The long-term facilitation is dependent on protein and mRNA syntheses (Montarolo et al., 1986; Martin et al., 1997). The heterosynaptic facilitation in Aplysia is a cellular basis for the behavioral sensitization of gill-withdrawal reflex (Castellucci and Kandel, 1976). The treatment with a protein synthesis inhibitor, which specifically suppresses the long-term facilitation blocks, the long-term, but not the short-term, sensitization (Castellucci et al., 1989). The common properties of these three forms of synaptic plasticity are noticed. First, there are distinct early and late phases. Second, the late phase is dependent on protein and mRNA syntheses. Third, the late phase is induced by more intensive stimulation than that of the early phase. In the hippocampus and Aplysia, the early phase and the late phase are suggested to be responsible for the short-term and the long-term memory, respectively. The early and the late phases of the DME might also have distinct functional roles.

\section{Critical periods for mRNA and protein syntheses for the late phase}

As for the hippocampal LTP, the application of a protein synthesis inhibitor $35 \mathrm{~min}$ after the induction had no effect on the late phase (Frey and Morris, 1997). In Aplysia, mRNA and protein synthesis inhibitors were not effective in suppressing long-term facilitation when applied 30 min after the end of 5-HT application (Montarolo et al., 1986). In the cerebellar LTD, Linden (1996) reported that application of anisomycin $30 \mathrm{~min}$ after the induction did not affect the LTD of glutamate responsiveness. These studies showed that there are critical periods for mRNA and protein syntheses necessary for the late phase. In the present study, we showed that there are critical periods for mRNA and protein synthesis in the DME. The critical period for mRNA synthesis ended by $50 \mathrm{~min}$ and that for protein synthesis lasted for 12-20 hr. The most likely interpretation seems that mRNAs synthesized within $1 \mathrm{hr}$ after the induction are stable and that proteins necessary to maintain the late phase are continuously translated from them for $>12 \mathrm{hr}$. The cause of difference between a previous report (Linden, 1996) and our results is unclear. In addition to the early and late phases, there might be an intermediate phase that requires protein synthesis only for its induction but not for its maintenance.

\section{REFERENCES}

Abel T, Nguyen PV, Barad M, Deuel TAS, Kandel ER, Bourtchuladze R (1997) Genetic demonstration of a role for PKA in the late phase of LTP and in hippocampus-based long-term memory. Cell 88:615-626.

Abraham WC, Mason SE, Demmer J, Williams JM, Richardson CL, Tate W P, Lawlor PA, Dragunow M (1993) Correlations between immediate early gene induction and the persistence of long-term potentiation. Neuroscience 56:717-727.

Aiba A, Kano M, Chen C, Stanton ME, Fox GD, Herrup K, Zwingman TA, Tonegawa S (1994) Deficient cerebellar long-term depression and impaired motor learning in mGluR1 mutant mice. Cell 79:377-388.

Bourtchuladze R, Frenguelli B, Blendy J, Cioffi D, Schutz G, Silva AJ (1994) Deficient long-term memory in mice with a targeted mutation of the cAMP-responsive element-binding protein. Cell 79:59-68.

Castellucci V, Kandel ER (1976) Presynaptic facilitation as a mechanism for behavioral sensitization in Aplysia. Science 194:1176-1178.

Castellucci VF, Blumenfeld H, Goelet P, Kandel ER (1989) Inhibitor of protein synthesis blocks long-term behavioral sensitization in the isolated gill-withdrawal reflex of Aplysia. J Neurobiol 20:1-9.

Conquet F, Bashir ZI, Davies CH, Daniel H, Ferraguti F, Bordi F, Franz-Bacon K, Reggiani A, Matarese V, Conde F, Collingridge GL, Crepel F (1994) Motor deficit and impairment of synaptic plasticity in mice lacking mGluR1. Nature 372:237-243.

Crepel F, Jaillard D (1991) Pairing of pre- and postsynaptic activities in cerebellar Purkinje cells induces long-term changes in synaptic efficacy in vitro. J Physiol (Lond) 432:123-141.

du Lac S, Raymond JL, Sejnowski TJ, Lisberger SG (1995) Learning and memory in the vestibulo-ocular reflex. Annu Rev Neurosci 18:409-441.

Frey U, Morris RGM (1997) Synaptic tagging and long-term potentiation. Nature 385:533-536.

Frey U, Krug M, Reymann KG, Matthies H (1988) Anisomycin, an inhibitor of protein synthesis, blocks late phases of LTP phenomena in the hippocampal CA1 region in vitro. Brain Res 452:57-65.

Hirano T (1990a) Depression and potentiation of the synaptic transmission between a granule cell and a Purkinje cell in rat cerebellar culture. Neurosci Lett 119:141-144. 
Hirano T (1990b) Effects of postsynaptic depolarization in the induction of synaptic depression between a granule cell and a Purkinje cell in rat cerebellar culture. Neurosci Lett 119:145-147.

Hirano T (1991) Differential pre- and postsynaptic mechanisms for synaptic potentiation and depression between a granule cell and a Purkinje cell in rat cerebellar culture. Synapse 7:321-323.

Hirano T, Hagiwara S (1988) Synaptic transmission between rat cerebellar granule and Purkinje cells in dissociated cell culture: Effects of excitatory-amino acid transmitter antagonists. Proc Natl Acad Sci USA 85:934-938.

Hirano T, Kasono K (1993) Spatial distribution of excitatory and inhibitory synapses on a Purkinje cell in a rat cerebellar culture. J Neurophysiol 70:1316-1325.

Hirano T, Ohmori H (1986) Voltage-gated and synaptic currents in rat Purkinje cells in dissociated cell cultures. Proc Natl Acad Sci USA 83:1945-1949.

Ito M (1989) Long-term depression. Annu Rev Neurosci 12:85-102.

Ito M, Sakurai M, Tongroach P (1982) Climbing fibre induced depression of both mossy fibre responsiveness and glutamate sensitivity of cerebellar Purkinje cells. J Physiol (Lond) 324:113-134.

Kasono K, Hirano T (1994) Critical role of postsynaptic calcium in cerebellar long-term depression. NeuroReport 6:17-20.

Konnerth A, Dreessen J, Augustine GJ (1992) Brief dendritic calcium signals initiate long-lasting synaptic depression in cerebellar Purkinje cells. Proc Natl Acad Sci USA 89:7051-7055.

Linden DJ (1994) Long-term synaptic depression in the mammalian brain. Neuron 12:457-472.

Linden DJ (1996) A protein synthesis-dependent late phase of cerebellar long-term depression. Neuron 17:483-490.

Linden DJ (1998) Synaptically evoked glutamate transport currents may be used to detect the expression of long-term potentiation in cerebellar culture. J Neurophysiol 79:3151-3156.
Linden DJ, Connor JA (1995) Long-term synaptic depression. Annu Rev Neurosci 18:319-357.

Linden DJ, Dickinson MH, Smeyne M, Connor JA (1991) A long-term depression of AMPA currents in cultured cerebellar Purkinje neurons. Neuron 7:81-89.

Lisberger SG (1998) Cerebellar LTD: a molecular mechanism of behavioral learning? Cell 92:701-704.

Martin KC, Casadio A, Zhu H, E Y, Rose JC, Chen M, Bailey CH, Kandel ER (1997) Synapse-specific, long-term facilitation of Aplysia sensory to motor synapses: A function for local protein synthesis in memory storage. Cell 91:927-938.

Mauk MD, Garcia KS, Medina JF, Steele PM (1998) Does cerebellar LTD mediate motor learning? Toward a resolution without a smoking gun. Neuron 20:359-362.

Montarolo PG, Goelet P, Castellucci VF, Morgan J, Kandel ER, Schacher S (1986) A critical period for macromolecular synthesis in long-term heterosynaptic facilitation in Aplysia. Science 234:1249-1254.

Nguyen PV, Abel T, Kandel ER (1994) Requirement of a critical period of transcription for induction of a late phase of LTP. Science 265:1104-1107.

Sakurai M (1987) Synaptic modification of parallel fibre-Purkinje cell transmission in in vitro guinea-pig cerebellar slices. J Physiol (Lond) 394:463-480.

Sakurai M (1990) Calcium is an intracellular mediator of the climbing fiber in induction of cerebellar long-term depression. Proc Natl Acad Sci USA 87:3383-3385.

Salin PA, Malenka RC, Nicoll RA (1996) Cyclic AMP mediates a presynaptic form of LTP at cerebellar parallel fiber synapses. Neuron 16:797-803.

Shigemoto R, Abe T, Nomura S, Nakanishi S, Hirano T (1994) Antibodies inactivating mGluR1 metabotropic glutamate receptor block longterm depression in cultured Purkinje cells. Neuron 12:1245-1255. 